SISTEMA
ELETROANICO
DE REVISTAS
SER I UFPR

\title{
Representações sociais do Rio Doce e suas enchentes em Governador Valadares/Brasil
}

\section{Social representations of the Doce River and its floodings in Governador Valadares/Brazil}

\author{
Maria Marta Amancio AMORIMํ, Gabriel Henrique de Oliveira ASSUNÇÃO², Ana Carolina DIAS³, Gilvan \\ Ramalho GUEDES ${ }^{*}$ \\ ${ }^{1}$ Investigadora do Centro de Estudos em Migrações e Relações Interculturais da Universidade Aberta de Lisboa, Portugal. \\ ${ }^{2}$ Instituto Brasileiro de Geografia e Estatística (IBGE), Rio de Janeiro, RJ, Brasil. \\ ${ }^{3}$ Departamento de Estatística, Universidade Federal de Minas Gerais (UFMG), Belo Horizonte, MG, Brasil. \\ ${ }^{4}$ Departamento de Demografia, Universidade Federal de Minas Gerais (UFMG), Belo Horizonte, MG, Brasil. \\ *E-mail de contato: grguedes@cedeplar.ufmg.br
}

Artigo recebido em 3 de fevereiro de 2018, versão final aceita em 29 de outubro de 2018.

RESUMO: As enchentes regulares do Rio Doce geram grandes transtornos aos moradores de Governador Valadares, expondo-os a riscos epidemiológicos devido ao elevado índice de poluição hídrica. Os modos de vidas e práticas culturais das pessoas que vivem às margens de um rio são criados e recriados por meio das suas vivências, sentidos e representações sociais. Assim, este estudo pretende caracterizar as representações sociais dos moradores de Governador Valadares sobre o Rio Doce e suas enchentes, que foram afetados ou não por elas. Utilizou-se a associação livre de palavras com justificativa das respostas para levantar as representações de 268 residentes de Governador Valadares em relação ao Rio Doce e as suas enchentes. As representações sociais dos dois grupos foram comparadas. Este estudo fundamenta-se na teoria das representações sociais, nomeadamente a teoria do núcleo central, que contém uma abordagem metodológica múltipla que associa aspectos qualitativos e quantitativos no levantamento e análise dos dados. Os dados analisados pelo software Ensemble de Programmes Permettant l'Analyse des Évocations (Evoc) geraram os quadros de quatro casas. Os moradores afetados ou não pelas enchentes representam o Rio Doce como um rio poluído, sendo a poluição o núcleo central. A perda é o provável núcleo central da palavra "enchente" evocada pelas pessoas que moram em Governador Valadares, afetadas ou não pela enchente. Os núcleos centrais "poluição" para o Rio Doce e "perda" para enchente entre os moradores afetados e os não afetados mostraram que houve homogeneidade de pensamento representacional entre os dois grupos. O Rio Doce e suas enchentes geraram representações sociais, pois são objetos que incomodam os cidadãos de Governador Valadares. Os mecanismos de adaptação 
a cada nova enchente e a resiliências daqueles que experimentaram as diversas enchentes atuais poderão ser entendidos a partir de experiências daqueles que sofreram o evento.

Palavras-chave: representação social; ambiente; poluição hídrica.

ABSTRACT: The regular floods of the Rio Doce poses great inconveniences to the residents of Governador Valadares, exposing them to epidemiological risks due to the pollution in the river water. The livelihoods and cultural practices of people living on the banks of a river are created and recreated through their experiences, senses, and social representations. Thus this study characterizes the social representations of the residents of Governador Valadares that were affected or not by the Rio Doce floods. The free association of words technique with answers justification was used to raise the representations of 268 residents of Governador Valadares in relation to Rio Doce and its floods. The social representations of the two groups were compared. This study is based on the theory of social representations, namely the central core theory, which contains a multiple methodological approach that associates qualitative and quantitative aspects in the collection and analysis of data. The data analyzed by the software Ensemble of Programs Permettant l'Analyze des Évocations (EVOC) were classified in four quadrants. Residents affected or not by the floods signify the Rio Doce as a polluted river, with pollution being the central nucleus. The "loss" is the probable central nucleus of the word Flood evoked by people living in Governador Valadares, affected or not by the flood. Central nuclei pollution of the Rio Doce and loss due to flood between affected and non-affected residents suggests that there is some degree of homogeneity in the representational thinking between the two groups. The Rio Doce and its floods were expressions able to yield social representations, because they are intimate objects to the citizens of Governador Valadares, evoking positive and negative feelings and meanings around them. The mechanisms of adaptation to each new flood and the resilience of those who have experienced the various current floods can be understood from the experiences of those who have suffered the event.

Keywords: social representation; environment; water pollution.

\section{Introdução}

O Rio Doce percorre grande parte do estado de Minas Gerais e do Espírito Santo, sendo a mais importante bacia totalmente incluída na região Sudeste e uma das principais fontes de sustento de pesca e outros recursos nas cidades banhadas, como Governador Valadares (Phir Doce, 2010). Essa cidade apresenta um histórico de enchentes regulares em decorrência do alto nível de assoreamento das suas margens (Brasil, 2006).

As constantes inundações representam um sério problema para os residentes das áreas inseridas na planície de inundação (Igam, 2010). Inundações referem-se a um tipo particular de enchente, na qual a elevação do nível d'água normal atinge tal magnitude que as águas não se limitam à calha principal do rio, extravasando para áreas marginais, habitualmente não ocupadas pelas águas, registradas nos períodos chuvosos, de outubro a março, com maior incidência nos meses de dezembro a fevereiro.

A urbanização não planejada dos municípios banhados pelo Rio Doce gera problemas que, na atualidade, afetam a qualidade ambiental. Além dos impactos ambientais causados à bacia, destaca-se a ausência ou a ineficiência do saneamento básico, em que os esgotos domésticos, resíduos sólidos urbanos e rejeitos industriais, sem tratamento, são lançados 
in natura nesse rio, alterando os parâmetros que definem a qualidade de suas águas. Em decorrência disso, o Rio Doce interfere diretamente na qualidade de vida das populações que se utilizam desse recurso, quer seja para consumo, trabalho e lazer, uma vez que contribui para o aumento da incidência das doenças de veiculação hídrica (Hora et al., 2012).

Além dos moradores, o governo municipal, a sociedade civil organizada, as lideranças comunitárias estão envolvidos nas enchentes de Governador Valadares, que revelam tensões e articulações fundamentais para a melhor compreensão do surgimento da territorialização dos bairros ribeirinhos e da própria relação entre a sociedade e o território (Guedes et al., 2012). Assim, o Rio Doce com suas enchentes frequentes consiste em um elemento fundamental na leitura dos territórios forjados pelas comunidades que dele dependem, constroem sua existência e retiram o sustento de suas vidas. Existem populações que estabelecem fortes ligações com os rios que, além de proverem a água, tornam-se parte integrante de sua história de vida (Porath, 2004; Almeida \& Carvalho, 2010; Hora, 2013). Os modos de vidas e práticas culturais das pessoas que vivem às margens de um rio são criados e recriados e os indivíduos, grupos sociais e comunidades por meio das vivências e sentidos, elaboram percepções diferenciadas uns dos outros. Essas percepções compõem-se das experiências individuais, dos aprendizados, das sucessões de fatos que determinam vínculos, atribuem valores, constroem símbolos que norteiam condutas e comportamentos nos lugares em que suas vidas foram fixadas (Sampaio \& Vargas, 2010).

Para compreender o pensamento coletivo referente ao meio ambiente, Oliveira et al. (2015) utilizaram a teoria da representação social e concluíram que as representações são expressas nos discursos e nas atitudes, criando uma imagem ou campo de representações desse objeto. Fagundes (2015) ressalta que é fundamental entender que o homem pratica determinadas ações no meio ambiente por razões principalmente culturais e a representação social é um instrumento valioso e imprescindível no campo da Geografia cultural. Nessa direção, Hora (2013) identificou as representações sociais da comunidade de Tumiritinga sobre o Rio Doce, concluindo que esse rio é percebido por sua essencialidade, ou seja, pela sua utilidade como elemento imprescindível à sobrevivência humana.

Assim, na tentativa de melhor compreender a percepção dos residentes de Governador Valadares sobre o Rio Doce e suas enchentes, será utilizada a Teoria das Representações Sociais (TRS). Uma representação sempre é de alguém (o sujeito) e de alguma coisa (o objeto). Deve-se levar em consideração simultaneamente o sujeito e o objeto da representação a ser estudados (Sá, 1998), fato que contribuiu para selecionar os moradores de Governador Valadares como os sujeitos sociais. Como objetos da representação, selecionou-se estudar o Rio Doce e as suas enchentes. Segundo Sá (1998), é necessário simplificar o complexo fenômeno das representações sociais para que ele se torne compreensível pelo fundamento da TRS e defini-lo com base na finalidade da pesquisa, que seleciona e delimita as dimensões ou aspectos do fenômeno a ser estudado.

Assim, este estudo pretende caracterizar as representações sociais, sobre o Rio Doce e suas enchentes, dos moradores de Governador Valadares que foram afetados ou não por elas. 


\section{Percurso metodológico}

Este estudo fundamenta-se na TRS, na abordagem estrutural, denominada teoria do núcleo central, que contém uma abordagem metodológica múltipla que associa aspectos qualitativos e quantitativos no levantamento e análise dos dados (Campos, 2003). Essa teoria, elaborada por Jean-Claude Abric, descreve a estruturação interna das representações sociais estabilizadas, que organiza sistemas central e periférico, com características e funções distintas (Abric, 1994).

As representações sociais não são simples opiniões, mas são "teorias" do senso comum, são construções esquemáticas que as pessoas elaboram para dar conta da complexidade do objeto, facilitar a comunicação e orientar condutas. Elas são sistemas que têm uma lógica e uma linguagem particulares, uma estrutura de implicações baseada em valores e conceitos, e que determinam o campo das comunicações possíveis, dos valores ou das ideias compartilhadas pelos grupos e regem, subsequentemente, as condutas desejáveis ou admitidas (Moscovici, 2012). A representação social é a construção mental da realidade, que possibilita a compreensão e a organização do mundo, bem como orienta o comportamento das pessoas (Moscovici, 2004).

Para coletar os dados referentes às representações sociais dos moradores de Governador Valadares, utilizou-se a Técnica de Associação Livre de Palavras que permite colocar em evidência o universo semântico do objeto estudado, assim como a sua dimensão imagética, de forma mais rápida e dinâmica que outros métodos com igual objetivo (Abric, 2001; Sá, 2002). O entrevistador solicitou aos sujeitos afetados ou não pelas enchentes que verbalizassem cinco palavras ou expressões que thes ocorressem imediatamente em relação aos termos indutores "Rio Doce" e "enchentes". Cada entrevistado enumerou, numa escala de 1 a 5 , as evocações por ordem crescente de importância (Abric, 2003), justificando a mais importante.

O tratamento dos dados coletados foi realizado por meio do software Ensemble de Programmes Permettant l'Analyse des Évocations (Evoc), versão 2003 (Vergès, 2000). Para a construção do corpus de análise, cada palavra foi digitada em seu formato original, em duas planilhas Excel, uma na ordem em que as palavras foram lembradas (corpus evocado) e outra na ordem de importância atribuída pelos sujeitos (corpus hierarquizado), segundo o modelo do software. Cada evocação do corpus original foi substituída por seu respectivo termo padrão, com base no dicionário de palavras produzidas pela população de sujeitos. O software calculou e informou, para cada termo indutor, a frequência simples de ocorrência de cada palavra, a média ponderada de ocorrência de cada palavra em função da ordem de evocação e a média das ordens ponderadas do conjunto dos termos evocados (Oliveira, 2005).

Com base nesses valores de corte, foram compostas as informações para a construção do "quadro de quatro casas", por meio do qual é especificado o núcleo central, os elementos de contraste e os elementos periféricos da representação (Sá, 2002; Oliveira, 2005). Foram construídos dois quadros de quatro casas para a representação social "Rio Doce" e dois quadros para a representação social "enchentes", dos moradores afetados ou não pela enchente. A frequência e o valor médio da ordem de evocação de cada termo com os valores de corte dos quadrantes foram comparados e procedeu-se à interpretação dos mesmos (Oliveira, 2005). Os 
dados qualitativos referentes às justificativas da palavra mais importante evocada foram apresentados e serviram para dar vida à representação analisada pela técnica da análise de conteúdo temático-categorial (Bardin, 2010), fundamentado na teoria do núcleo central das representações sociais.

Os sujeitos dessa pesquisa (268) foram selecionados dos primeiros dados coletados do projeto realizado em Governador Valadares intitulado "Migração, Vulnerabilidade e Mudanças Ambientais no Vale do Rio Doce". A amostra, superior a 100, foi suficiente para analisar os dados pelo software Evoc. O projeto foi aprovado pelo Comitê de Ética e Pesquisa da Universidade Federal de Minas Gerais, número 12650413.0.0000.5149, em 03 de fevereiro de 2014.

Por meio de entrevista foram obtidas as seguintes informações para caracterizar a amostra estudada: idade, sexo, naturalidade, distância de moradia do rio, estado civil e classe socioeconômica. O critério de classificação socioeconômica utilizada seguiu a proposta de classificação da Associação Brasileira de Empresas de Pesquisa (Abep, 2014).

A amostra foi distribuída entre os moradores afetados ou não pelas enchentes, para verificar as diferenças entre esses dois grupos, pois a cidade de Governador Valadares sofreu constantes inundações que representaram um sério problema para essas pessoas. A caracterização da amostra e da região estudada são descritas a seguir.

\subsection{Caracterização da amostra estudada}

Os dados sociodemográficos foram distribuídos pelos moradores afetados ou não pelas enchen- tes com a intenção de caracterizar o contexto cultural e social dos participantes da pesquisa (Tabela 1).

Dos moradores de Governador Valadares estudados $40 \%$ foram afetados pelas enchentes, sendo $57 \%$ do sexo feminino e $43 \%$ do masculino, predominando as mulheres. Esses dados caracterizam a população de Governador Valadares em que predominam as mulheres, de acordo com o censo de 2010 (IBGE, 2010a). Dos moradores avaliados, $49 \%$ são naturais de Governador Valadares e 52\% nasceram em outras cidades. A idade média é de 42 anos. Quanto ao estado civil, $43 \%$ são casados - dados semelhantes ao estudo de Hora (2013) que avaliou as representações sociais dos moradores de Tumiritinga sobre o Rio Doce -, 35\% são solteiros e os demais viúvos, divorciados ou união estável. Essas pessoas moram, em média, a 1067 metros de distância do Rio Doce.

Segundo o Critério de Classificação Socioeconômica Brasil proposto pela Abep (2014), 11,2\% dos moradores pertencem à classe socioeconômica $\mathrm{D} / \mathrm{E}, 42 \%$ pertencem à classe $\mathrm{C}, 39,3 \%$ à classe $\mathrm{B}$ e $7,5 \%$ à classe $\mathrm{A}$. Para os moradores afetados pelas enchentes, predominam aqueles que se classificam nas classes socioeconômicas referentes aos estratos socioeconômicos C e B. Esse critério, conhecido como Classificação Socioeconômica Brasil (ou simplesmente Critério Brasil), utiliza um sistema de pontos que varia de 0 a 46 . Esses pontos são baseados em perguntas relativas ao grau de instrução do chefe de família e a uma seleção de número de bens duráveis (nove tipos de bens). Para cada resposta é assinalado um peso específico, como descrito em Abep (2014), e a soma dos pontos define a escala final. Para a transformação dessa escala em classes socioeconômicas, foram utilizados os cortes do Critério Brasil definido pela Abep, como se segue: 
A - de 35 a 46 pontos; B - de 23 a 34 pontos; C - de 14 a 22 pontos; D de 8 a 13 pontos; e $\mathrm{E}$ - de 0 a 7 pontos.

Os moradores não afetados (60\%) são superiores aos afetados pelas enchentes, sendo 63\% mulheres e $37 \%$ homens, $45 \%$ são naturais de Governador Valadares e $55 \%$ nasceram em outros municípios. A idade média é de 44 anos, sendo que $49 \%$ são casados, $32 \%$ solteiros, $11 \%$ viúvos e os demais divorciados e união estável. Embora não tenham sido afetados pelas enchentes, eles moram a uma distância um pouco menor do Rio Doce: 911,59 metros, em relação aos afetados. Quanto às classes socioeconômicas, $13 \%$ dos moradores pertencem à $\mathrm{D} / \mathrm{E}, 49,7 \%$ pertencem à $\mathrm{C}, 33,6 \%$ à $\mathrm{B}$ e $3,7 \%$ à classe A, segundo a classificação da Abep (2014). A renda familiar média dos moradores não afetados é similar aos dos moradores afetados.

Verificou-se que dentre as características sociodemográficas avaliadas não há grandes diferenças entre os moradores afetados e os não afetados pelas enchentes.

TABELA 1 - Características sociodemográficas dos moradores afetados e não afetados pelas enchentes.

\begin{tabular}{|c|c|c|c|c|c|c|}
\hline & Afetados & & Não afetados & & Total & \\
\hline Variáveis & $\mathbf{N}$ & $\%$ & $\mathbf{N}$ & $\%$ & $\mathbf{N}$ & $\%$ \\
\hline \multicolumn{7}{|l|}{ Sexo } \\
\hline Masculino & 46 & 43 & 60 & 37 & 106 & 40 \\
\hline Feminino & 61 & 57 & 101 & 63 & 162 & 60 \\
\hline Idade média (anos) & \multicolumn{2}{|l|}{$42,07 \pm 16,45$} & \multicolumn{2}{|l|}{$44,14 \pm 17,95$} & & \\
\hline \multicolumn{7}{|l|}{ Naturalidade } \\
\hline Governador Valadares & 52 & 48,6 & 72 & 44,7 & 124 & 46,3 \\
\hline Outras cidades & 55 & 51,4 & 89 & 55,3 & 144 & 53,7 \\
\hline Distância (metros) rio & 1067,27 & & 911,59 & & & \\
\hline \multicolumn{7}{|l|}{ Estado civil } \\
\hline Casado & 46 & 43,0 & 79 & 49,0 & 125 & 46,6 \\
\hline Solteiro & 41 & 38,3 & 51 & 31,7 & 92 & 34,3 \\
\hline União-estável & 06 & 5,6 & 06 & 3,7 & 12 & 4,5 \\
\hline Viúvo & 04 & 3,7 & 17 & 10,6 & 21 & 7,8 \\
\hline Divorciado & 10 & 9,4 & 08 & 5,0 & 18 & 6,8 \\
\hline \multicolumn{7}{|l|}{ Classe socioeconômica } \\
\hline A & 8 & 7,5 & 6 & 3,70 & 14 & 5,20 \\
\hline B & 42 & 39,3 & 54 & 33,6 & 96 & 35,8 \\
\hline $\mathrm{C}$ & 45 & 42,0 & 80 & 49,7 & 125 & 46,6 \\
\hline $\mathrm{D} / \mathrm{E}$ & 12 & 11,2 & 21 & 13,0 & 33 & 12,4 \\
\hline
\end{tabular}

FONTE: os autores. 


\subsection{Caracterização da região estudada}

O município de Governador Valadares está localizado na mesorregião do Vale do Rio Doce, uma das 12 mesorregiões de Minas Gerais formada por sete microrregiões que englobam 102 municípios. Está a cerca de $320 \mathrm{~km}$ de distância da capital, Belo Horizonte, 276.995 habitantes sendo o nono município mais populoso de Minas Gerais. Esse município ocupa uma área de $2348,1 \mathrm{~km}^{2}$, sendo, deste total, $24,3674 \mathrm{~km}^{2}$ de perímetro urbano (IBGE, 2013). A maior parte de Governador Valadares situa-se na margem esquerda do Rio Doce, formado pelos rios Piranga e Carmo, cujas nascentes estão situadas nas encostas das serras da Mantiqueira e Espinhaço (Figura 1). A cidade ainda é cortada pelos rios Suaçuí Grande e Suaçuí Pequeno. Com 853 km de extensão da nascente à foz, o Rio Doce nasce no município de Ressaquinha/MG, onde recebe o nome de Piranga, e deságua no oceano Atlântico, no povoado de Regência, no município de Linhares/ ES (Phir Doce, 2010).

O Rio Doce está inserido na Bacia Hidrográfica do Rio Doce e constitui-se em uma das principais bacias inseridas na região do Atlântico Sudeste. A sua extensão territorial recobre, em maior proporção, a região centro-leste do estado de Minas Gerais $(86,1 \%)$ e, em menor, a região centro-norte do Espírito Santo (13,9\%), sendo, portanto, uma bacia de domínio federal (Coelho, 2007).

O intenso desflorestamento, a erosão, o assoreamento e a poluição advindos da ocupação e urbanização não planejada da Bacia Hidrográfica do Rio Doce fizeram com que essa seja, atualmente, a $10^{\mathrm{a}}$ mais poluída do Brasil, dentre os rios avaliados (IBGE, 2010b).
A cidade de Governador Valadares, no seu processo de ocupação, emergiu como um polo comercial do Médio Rio Doce, com a estrada de ferro e o rio cortando a cidade. Desde 1940 apresenta deficiências do fornecimento de água potável, energia elétrica e saneamento básico (Genovez \& Vilarino, 2010). A água utilizada pela população para consumo humano era retirada da própria bacia, havendo uma dependência crucial em relação ao rio, que representava uma condição de sobrevivência. A população convivia normalmente com as lagoas,

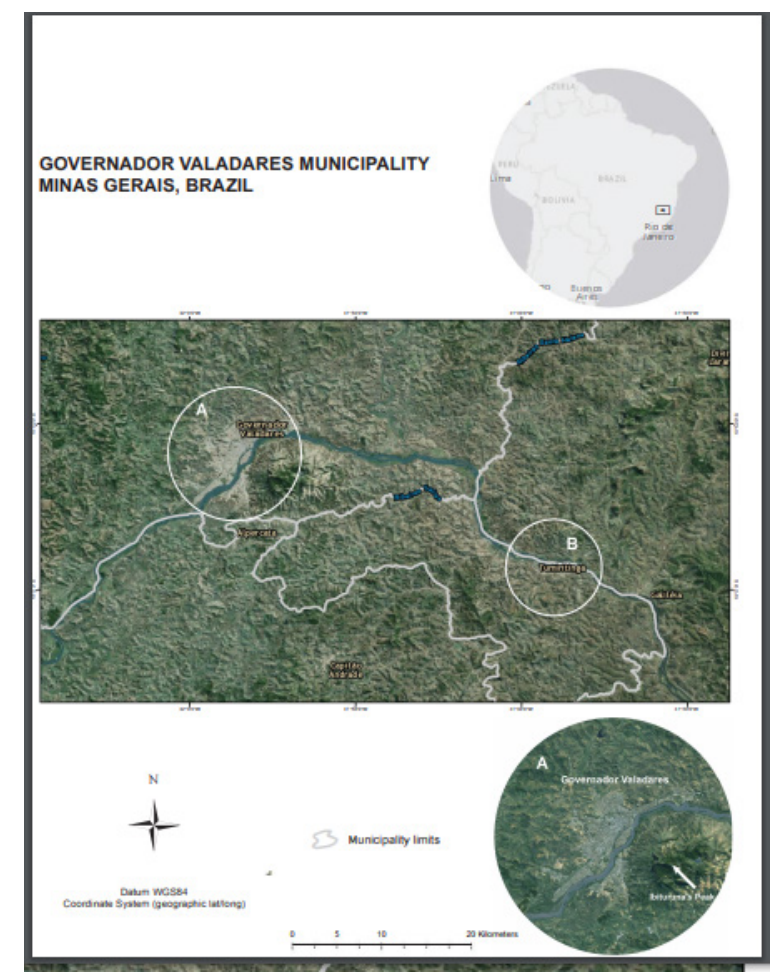

FIGURA 1 - Localização do município de Governador Valadares, em Minas Gerais.

FONTE: Malha Digital Municipal (IBGE, 2018); Imagens de Satélite de Base (Esri, 2012). 
pântanos e canais de uma cidade sem saneamento básico e água potável. O Rio Doce nessa época não se configurava pela população como uma percepção de risco; ao contrário, os novos moradores procuravam as margens do rio para construir suas casas (Guedes et al., 2012).

Em 1943 ruas foram abertas e pavimentadas, as lagoas foram esgotadas, os pântanos foram limpos, os esgotos foram escoados e a água foi tratada. A partir da década de 50 houve crescimento demográfico e expansão da malha urbana acelerada, que avançou para além da faixa ribeirinha. A população volta, então, a conviver com os pântanos, canais e frequentes alagamentos cheios de lixo, não somente às margens do rio, mas em todos os bairros da cidade. Na visão da população, a enchente que ocorreu em 1964 não foi devido ao Rio Doce e sim à falta de atenção do governo municipal para a malha urbana sem infraestrutura adequada (Guedes et al., 2012).

A pior enchente da história da cidade ocorreu em fevereiro de 1979, ao longo de toda a bacia do Rio Doce, com cerca de 47.776 desabrigados, 74 mortes e 4.424 residências atingidas (Folha on-line, 2003). A partir daí as enchentes entram no imaginário e na memória popular em função dos danos e da repercussão causada.

De menor impacto que a anterior, a enchente de 1985 teve uma grande repercussão e a de 1997 foi mais considerada uma calamidade pública. É importante ressaltar que a população permaneceu nos mesmos bairros e que novas áreas próximas ao rio foram ocupadas (Guedes et al., 2012).

\section{Resultados e discussão}

\subsection{Estruturas representacionais do "Rio Doce" evocadas pelos moradores de Governadores Valadares afetados pelas enchentes}

As quatro casas das evocações dos moradores de Governadores Valadares afetados pelas enchentes sobre o Rio Doce estão descritas na Tabela 2. A ordem média das evocações (OME) foi igual a 2,5, proporcionando a divisão do quadro em dois lados: direito, $\geq 2,5$, e esquerdo, $<2,5$. Ressalta-se que, quanto menor a OME, mais importantes são os atributos elencados. A frequência média de evocações (FME) foi igual a 10 e permitiu a divisão do quadro em mais duas casas: superior, $\geq 10$, e inferior, $<10$. Destaca-se que quanto maior a frequência maior será a importância do atributo.

No quadrante superior esquerdo, que agrupa os elementos mais frequentes e mais importantes, observa-se a presença do atributo "poluição", a maior FME de todas as evocações e o primeiro lugar em OME. Esse quadrante representa o núcleo central que é determinado pela natureza do objeto representado, pelas relações que o grupo mantém com o objeto e pelo sistema de valores e normas que norteiam o grupo. O núcleo central possui duas funções: geradora - cria ou transforma elementos da representação - e organizadora - unifica e estabiliza as representações. Possui uma dimensão quantitativa e outra qualitativa - dando significado à representação - e também tem um caráter normativo - expressa o normal, mas não o que é correto (Abric, 1994).

Os moradores que sofreram as consequências da enchente e moram próximo ao Rio Doce, cerca 
de 1067 metros, em média, deram significado à representação social "poluição", a responsável pelas enchentes, conforme relato: "porque ela (poluição) causa a enchente". Outro morador, de forma mais organizada, explica que a enchente é causada pelo lixo, um tipo de poluente: "é por causa dele, deste lixo que acontece (a enchente)". O Rio Doce é um objeto que faz parte da vida dessas pessoas. Segundo Fagundes (2015), o fenômeno da poluição da água, geralmente apontado pela ciência como um dos principais problemas ambientais, torna-se uma representação social quando esse passa a ser sentido pelas pessoas. Assim, passa a ser uma preocupação e começa a ser percebido e discutido no senso comum.

As representações sociais são "teorias" do senso comum, construções esquemáticas que as pessoas elaboram para dar conta da complexidade do objeto, facilitar a comunicação e orientar condutas. As representações sociais não são teorias coletivas sobre a imagem de alguma coisa, mas sim sobre a realidade. Elas são sistemas que têm uma lógica e uma linguagem particulares, uma estrutura de implicações baseada em valores e conceitos, e que determinam o campo das comunicações possíveis, dos valores ou das ideias compartilhadas pelos grupos e regem, subsequentemente, as condutas desejáveis ou admitidas. Essas "teorias" ajudam a forjar a identidade grupal e o sentimento de pertencimento do indivíduo ao grupo (Moscovici, 2012).

No estudo de Hora (2013), os moradores de Tumiritinga, uma comunidade também banhada pelo Rio Doce, evocaram como possível núcleo central da representação social sobre o Rio Doce a poluição. Observaram-se, pelas falas dos participantes, que a poluição das águas do Rio Doce exige cuidados que vão desde o reflorestamento de suas margens à despoluição de suas águas.

TABELA 2 - Quadro das quatro casas do termo indutor "Rio Doce" dos moradores de Governador Valadares afetados pelas enchentes. Governador Valadares/MG, 2014.

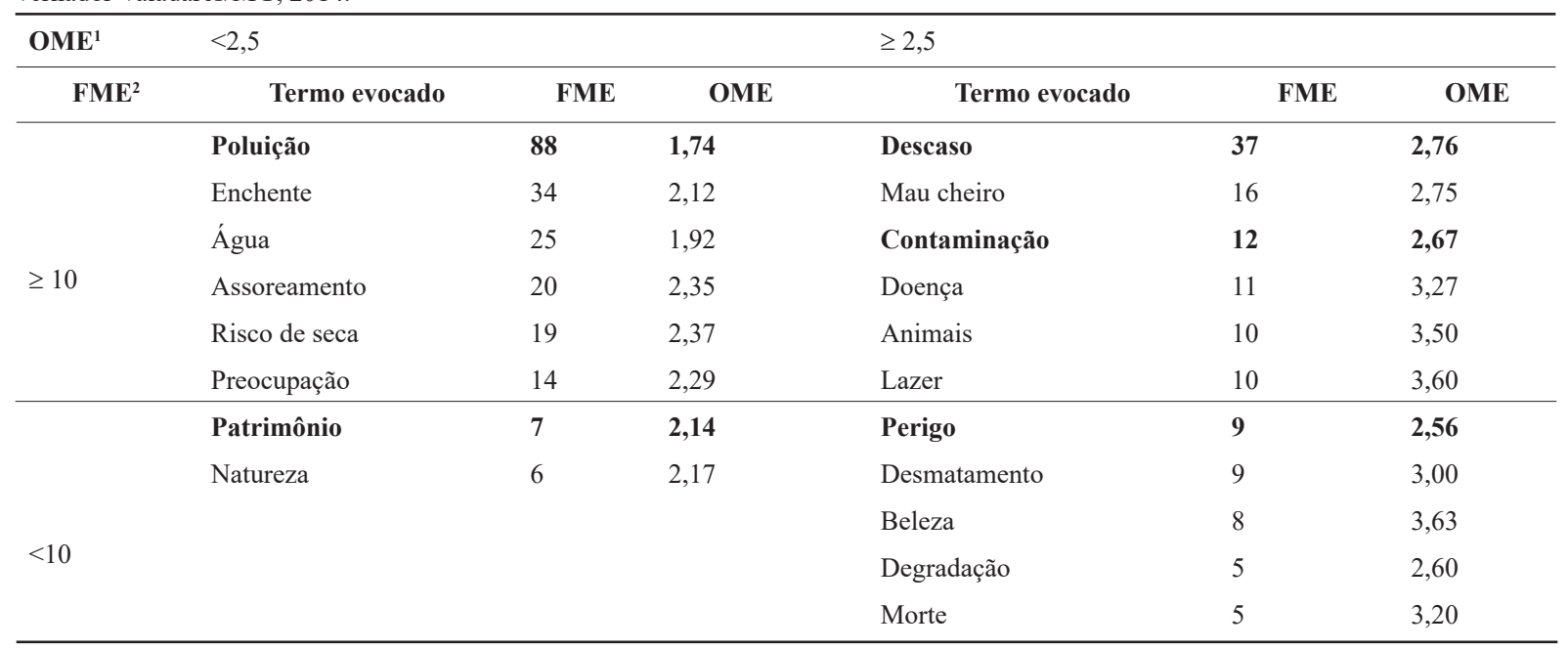

\footnotetext{
${ }^{1} \mathrm{OME}$ (ordem média de evocações); ${ }^{2} \mathrm{FME}$ (frequência média de evocações); ${ }^{3} \mathrm{FE}$ (frequência de evocação).
} FONTE: os autores. 
O atributo "poluição" é seguido de "água" e "enchente", que apresentam, respectivamente, o segundo e o terceiro lugares em importância em função da OME, seguidos de "preocupação", "assoreamento" e "risco de seca". Assim, os moradores de Governador Valadares afetados pelas enchentes julgam que Rio Doce possui poluídas águas, constantemente sujeitas às enchentes. Essas questões preocupam as pessoas, pois o assoreamento do rio é constante, podendo levar ao risco de seca.

Segundo Carvalho (2008), o assoreamento dos rios - acúmulo de detritos, lixo entulho e outros, no fundo dos rios interfere na topografia do leito dos rios, impedindo-os de portar cada vez menos água, provocando seu transbordamento em épocas de grande quantidade de chuvas.

Falar de enchente remete-nos à noção de risco - o potencial de ocorrência de perigo, como tratado na geografia física (Dagnino, 2007). Contudo, para a epidemiologia e a demografia, o risco está relacionado à probabilidade de ocorrência de um evento a pessoas que estão expostas a esse risco (Fraser et al., 2006). Na perspectiva humanista, o risco é uma interação de um perigo qualquer (enchente do Rio Doce) com um elemento (grupo social: moradores de Governador Valadares) exposto ao perigo e qualificado pela sua vulnerabilidade à ocorrência desse (Hogan \& Marandola Jr., 2005). Para as pessoas afetadas pela enchente, no senso comum, o risco significa a ocorrência de um evento de conotação negativa (Fraser et al., 2006).

No quadrante superior direito, onde se encontram os elementos periféricos mais importantes - primeira periferia -, observa-se a presença do atributo "descaso", a maior frequência de todas as evocações. Na visão de alguns entrevistados, o descaso refere-se aos moradores e aos governantes, conforme relatos: "Por que o povo que mora na beira não cuida e os governantes também não". "O descaso dos governantes leva a enchentes". "Porque aqui, quando deu a última enchente, a Ilha já estava lavada. Eles dão prioridade aos bairros mais favorecidos" e "Porque toda vez que cai um pouquinho de água já inunda tudo".

No estudo de Hora (2013) os moradores de Tumiritinga atribuem ser responsabilidade de todos os moradores estabelecerem práticas de usos conscientes, que não agridam o ambiente, bem como é dever dos governantes promover a fiscalização dessas práticas. A identificação dessas relações estabelecidas entre comunidades de Governador Valadares e Tumiritinga com o Rio Doce permitirá compreender até que ponto essas constituem-se em fatores favoráveis à conservação do Rio Doce, bem como ao bem-estar dessas comunidades, a despeito das inúmeras doenças hídricas que podem ser contraídas pela população, em razão da deficiente qualidade de suas águas.

Os atributos que possuem menor OME foram: "contaminação", "mau cheiro", "doença", "animais", "lazer". Esses atributos são denominados elementos periféricos e possuem as funções de concretização - ancoragem e regulação - mobilidade, evolução e defesa da representação (Abric, 2000). Os elementos periféricos também são ditos condicionais, uma vez que expressam o não frequente, o excepcional, mas não o anormal. Nesse quadrante aparecem os esquemas de funcionamento da representação, pois podem prescrever comportamentos, permitem a modulação das representações e das condutas, protegendo, assim, o núcleo central.

Dessa maneira, para os moradores de Governador Valadares afetados pelas enchentes, a "poluição", possível núcleo central da representação, 
gera contaminação, mau cheiro, doença, prejudica os animais e o lazer, devido ao descaso, na maioria das vezes, dos governantes, que não cuidam devidamente do Rio Doce.

Guedes et al. (2015) analisaram a associação entre percepção de contaminação e uso do Rio Doce, bem como os mecanismos heurísticos empregados na formação da percepção de risco. Os resultados revelaram que a maior parte dos entrevistados tem consciência da poluição do Rio Doce e de algumas fontes potenciais de tal poluição. Os problemas mais graves, para uma grande parcela, resultam das ações de indústrias localizadas na região, as quais contaminam a água ao lançarem produtos químicos no rio. Alguns entrevistados também ressaltaram o problema da poluição do rio como decorrente do lançamento de resíduos domésticos.

Observam-se no quadrante inferior esquerdo elementos que apresentam baixa frequência, mas são considerados importantes pelos sujeitos pela OME, como o atributo "patrimônio", com maior FME e menor OME, seguindo de "natureza". Esses atributos são denominados "zona de contraste" e revelam elementos que reforçam as noções presentes no núcleo central ou na primeira periferia, ou, ainda, a existência de um subgrupo minoritário portador de uma representação diferente (Oliveira, 2005). Nesse caso, as palavras evocadas "patrimônio" e "natureza" são representações positivas do Rio Doce, diferentemente das palavras evocadas no núcleo central, que têm características negativas do rio.

Dentre os elementos que se situam no quadrante inferior direito, e constituem os menos frequentes e menos importantes de toda a representação (Oliveira, 2005), encontra-se o atributo "perigo", maior FME e menor OME, seguidos de "degradação, "desmatamento", "morte" e "beleza". A OME do atributo "perigo" $(2,56)$ por estar muito próximo ao ponto de corte é uma representação importante a ser considerada, visto que, para os moradores que foram afetados pelas enchentes, esse evento é um perigo. As outras palavras negativas e o atributo positivo "beleza" acrescentam sentidos novos à representação. A “poluição", possível núcleo central da representação social dos moradores afetados pelas enchentes, é um perigo devido à degradação e ao desmatamento, podendo gerar morte e interferindo na beleza do Rio Doce.

\subsection{Estruturas representacionais do "Rio Doce” evocadas pelos moradores de Governadores Valadares não afetados pelas enchentes}

As quatro casas das evocações dos moradores de Governadores Valadares não afetados pelas enchentes sobre o Rio Doce estão descritas na Tabela 3. Dentre a palavra presente no quadrante superior esquerdo, com maior FME e menor OME, destaca-se "poluição" como provável elemento central da representação.

Os grupos de moradores de Governador Valadares não afetados e o de afetados pelas enchentes possuem os mesmos sistemas de valores e normas em relação ao objeto representado, o Rio Doce, um rio poluído. "As pessoas jogam lixo ou entulho no rio, assim fica cada vez mais poluído". O atributo "enchente" é a última palavra evocada pelos moradores não afetados e a segunda palavra mais evocada pelos moradores afetados. Nesse caso, o grupo de moradores não afetados, em sua atividade representativa, não reproduz passivamente um objeto dado (a enchente), pois não se constitui sujeito do evento, conforme explica Moscovici (2012). 
TABELA 3 - Quadro das quatro casas do termo indutor "Rio Doce" dos moradores de Governador Valadares não afetados pelas enchentes. Governador Valadares/MG, 2014.

\begin{tabular}{|c|c|c|c|c|c|c|}
\hline $\mathrm{OME}^{1}$ & $<2,5$ & & & $\geq 2,5$ & & \\
\hline $\mathbf{F M E}^{2}$ & Termo evocado & FME & OME & Termo evocado & FME & OME \\
\hline \multirow{10}{*}{$\geq 10$} & Poluição & 133 & 1,79 & Preocupação & 26 & 2,58 \\
\hline & Descaso & 47 & 2,12 & Assoreamento & 25 & 2,84 \\
\hline & Água & 45 & 2,31 & Desmatamento & 20 & 2,80 \\
\hline & Enchente & 33 & 2,49 & Animais & 18 & 2,89 \\
\hline & Perigo & 17 & 2,29 & Beleza & 15 & 2,93 \\
\hline & Risco de seca & 16 & 2,06 & Patrimônio & 11 & 2,82 \\
\hline & Vida & 12 & 2,08 & & & \\
\hline & Natureza & 12 & 2,42 & & & \\
\hline & Degradação & 11 & 2,27 & & & \\
\hline & Mau cheiro & 11 & 2,36 & & & \\
\hline \multirow{4}{*}{$<10$} & História & 6 & 2,17 & Morte & 9 & 2,67 \\
\hline & Tristeza & 5 & 2,00 & Lazer & 9 & 3,22 \\
\hline & Doença & 5 & 1,60 & Contaminação & 8 & 2,50 \\
\hline & & & & Difícil acesso & 6 & 3,5 \\
\hline
\end{tabular}

${ }^{1}$ OME (ordem média de evocações); ${ }^{2} \mathrm{FME}$ (frequência média de evocações); ${ }^{3} \mathrm{FE}$ (frequência de evocação).

FONTE: os autores.

Os principais atributos em menor OME foram "risco de seca", "vida", "descaso", "degradação", "perigo", "água", "mau cheiro", "natureza" e "enchente". Dessa maneira, os moradores não afetados pelas enchentes veem o Rio Doce como poluído, com risco de seca, fato que interfere na vida das pessoas, devido ao descaso e à degradação, sendo um perigo as suas águas com mau cheiro, que degradam a natureza e são sujeitas às enchentes.

O núcleo central é diretamente ligado e determinado pelas condições históricas, sociológicas e ideológicas. Ele é fortemente marcado pela memória coletiva do grupo e pelo sistema de normas ao qual ele define (Abric, 1994).

Utilizar a TRS para analisar a percepção dos moradores não afetados pelas enchentes foi funda- mental para compreender o evento, pois as representações sociais são, ao mesmo tempo, "produto e o processo de uma atividade mental, através do qual um indivíduo ou um grupo reconstitui a realidade com a qual ele se confronta e para a qual ele atribui um significado específico" (Abric, 1987, p. 64). Segundo Abric (1987), essa realidade é reapropriada pelo indivíduo ou pelo grupo, reconstruída em seu sistema cognitivo, integrada em seu sistema de valores, dependente de sua história de não ter vivenciado a enchente e também o contexto social e ideológico que o cerca, a cidade sujeita a constantes enchentes.

No quadrante superior direito, onde estariam os prováveis elementos periféricos, destacam-se "preocupação", maior frequência de menor ordem de evocação, seguidos de "desmatamento", "patri- 
mônio", "assoreamento", "animais", "beleza". Pode-se dizer que esses elementos periféricos podem prescrever comportamentos, além de permitirem a modulação das representações e das condutas, protegendo, assim, o núcleo central. Então a "poluição" do Rio Doce gera "preocupação" nos moradores não afetados, pois interfere no "patrimônio" da cidade, devido ao "desmatamento" das florestas e ao "assoreamento" do rio, além de prejudicar os "animais" e interferir na "beleza" do rio.

Nos possíveis elementos de contraste, destaca-se "história" como a palavra de maior FME e na OME crescente temos: "doença", "tristeza" e "história". Esses moradores não afetados possuem uma representação diferente, um rio que sempre causou doenças hídricas, conforme conta a história de Governador Valadares.

Já no quadrante inferior direito, destaca-se como segunda periferia a palavra "contaminação" como a mais frequente e de menor OME. Os outros atributos de menor OME são "morte", "lazer e "difícil acesso". Para esse grupo de pessoas não afetadas pelas enchentes, o Rio Doce é poluído, contaminado e pode levar à morte das pessoas, que deixam de ter lazer, devido ao difícil acesso.

\subsection{Estruturas representacionais das "enchentes" evocadas pelos moradores de Governadores Valadares afetados pelas enchentes}

As quatro casas das evocações dos moradores de Governadores Valadares afetados pelas enchentes sobre as "enchentes" estão descritas na Tabela 4. Dentre as palavras presentes no quadrante superior esquerdo, destaca-se "perda" como a mais frequente e o provável núcleo central da "enchente" evocada

TABELA 4 - Quadro das quatro casas do termo indutor "enchentes" dos moradores de Governador Valadares afetados pelas enchentes. Governador Valadares/MG, 2014.

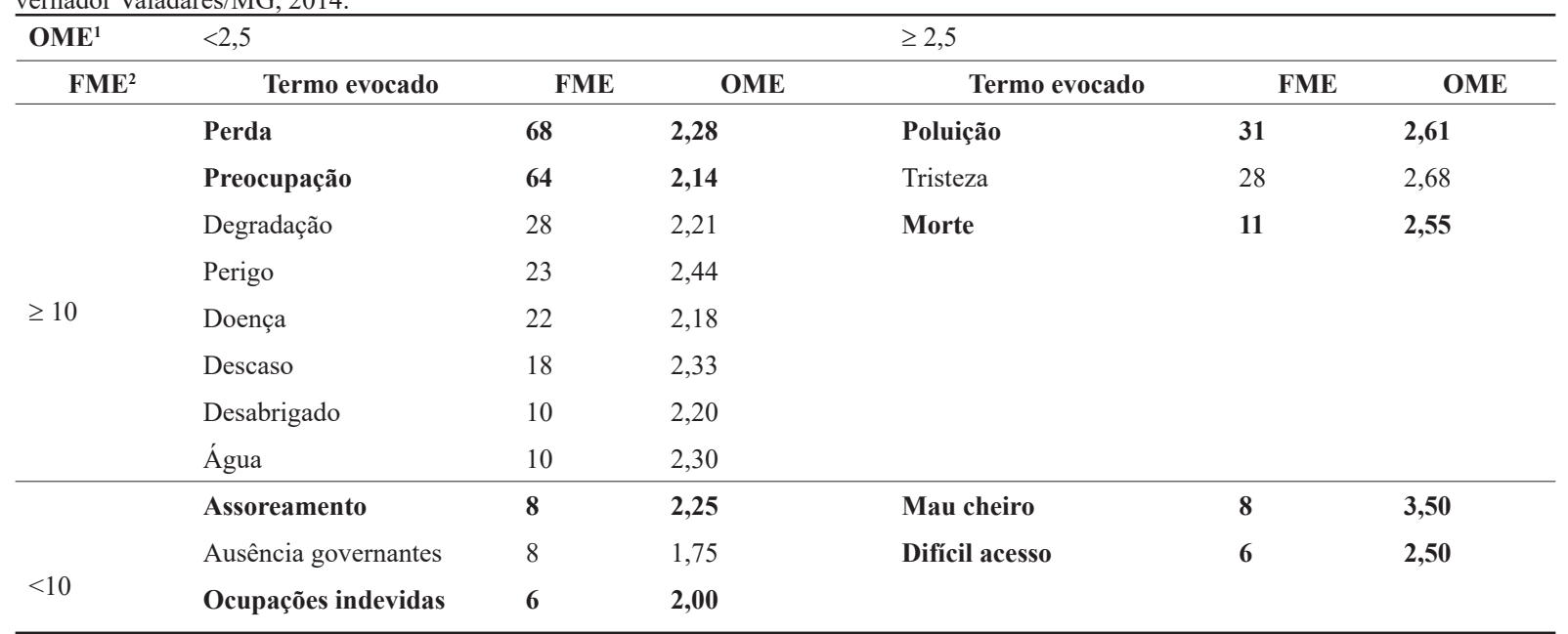

${ }^{1}$ OME (ordem média de evocações); ${ }^{2}$ FME (frequência média de evocações); ${ }^{3}$ FE (frequência de evocação). FONTE: os autores. 
pelos moradores de Governador Valadares afetados pelas enchentes: "Quando a água vem alta, estraga os móveis". "Às vezes você tem um móvel que custou a comprar, vem a enchente e leva tudo". "Tem gente que perde a reforma da casa, perde o carro".

Dessa forma as enchentes levam à perda dos móveis, casa e carro e, seguindo a OME, geram "preocupação", "doença", "desabrigados", devido à "degradação" ocasionada pela "água", ao "descaso" dos governantes, colocando em "perigo" a vida das pessoas. As enchentes do Rio Doce passam a ser percebidas como risco de perda, a partir do momento em que a população se apropria de uma área sujeita a esse tipo de evento e sofre danos significativos (Espíndola, 1998; 1999).

O risco depende dos fatores subjetivos que configuram a percepção dos moradores de Governador Valadares afetados pelas enchentes, além da natureza do perigo, potencial de exposição ao perigo existente, características dos elementos expostos, probabilidade de ocorrência do perigo, magnitude das consequências (Hogan \& Marandola Jr., 2005). Para haver risco, deve haver um perigo que o antecede. Como os moradores vivenciaram a enchente gerando danos materiais e humanos às suas vidas, provavelmente eles passaram pelo gerenciamento do risco, ou seja, passaram pela capacidade de adaptação e resiliência. A adaptação implica transformação (Jansen \& Ostrom, 2006) e a resiliência ocorre entre grupos de indivíduos expostos ao risco de determinado evento e que responderam a esse risco de forma bem-sucedida (Fraser et al., 2006).

Observa-se no quadrante superior direito a incorporação da palavra "poluição", a mais frequente, como possível elemento periférico. A "poluição", núcleo central da palavra evocada "Rio Doce" pelos moradores afetados ou não, passa a ser, para a palavra evocada "enchente" a primeira periferia. A "poluição" é prescritor de práticas, ou seja, na visão dos moradores afetados pelas enchentes, a perda provocada pelas enchentes é devido à poluição. $\mathrm{O}$ sistema periférico é funcional, isso quer dizer que é devido ao núcleo central que a representação pode se ancorar na realidade do momento (Abric, 1994). Além da poluição, os moradores afetados evocaram o atributo "morte" (menor OME) para expressar a enchente.

A "morte" protege a significação central da representação "perda", assim como a "poluição". De fato, no ano de 1979 uma forte e intensa chuva deixa vários mortos e desabrigados, em uma enchente que não atingiu apenas Governador Valadares, mas várias cidades localizadas ao longo das margens do Rio Doce e afluentes. Cerca de 10 mil ficaram desabrigados, pelo menos 42 morreram e cerca de 37 cidades ficaram inundadas, após mais de 35 dias de chuva entre janeiro e fevereiro daquele ano (Folha on-line, 2003).

Nos possíveis elementos de contraste destacam-se como os atributos mais frequentes "assoreamento" e "ausência" e com menor OME: "ausência", "ocupações indevidas" e "assoreamento". Para os moradores afetados, a enchente provoca perda devido ao "assoreamento", à "ausência" dos governantes e às "ocupações indevidas".

No quadrante inferior direito, destaca-se "mau cheiro" como a mais frequente, e de menor OME a palavra "difícil acesso". A enchente provoca perda, gera mau cheiro e dificulta o acesso ao Rio Doce.

\subsection{Estruturas representacionais das "enchentes" evocadas pelos moradores de Governadores Valadares não afetados pelas enchentes}

As quatro casas das evocações dos moradores de Governadores Valadares não afetados pelas 
enchentes sobre as "enchentes" estão descritas na Tabela 5. A evocação que surge, segundo a análise do Evoc, como conteúdo do núcleo central, de maior frequência para o termo "enchente" para os moradores não afetados pelas enchentes foi o atributo "perda". Dessa maneira os dois grupos de moradores afetados ou não consideram a enchente como "perda". Contudo para o segundo grupo a perda foi a palavra de menos importância $(\mathrm{OME}=2,33)$ do que para os afetados $(\mathrm{OME}=2,28)$. Para os não afetados a perda sempre é a do outro, conforme relatos: "significa a destruição dos bens de outras pessoas" ou "a enchente prejudica é quem mora em volta do rio, àqueles que moram perto. A gente que não fica longe, nem vê". Além disso, a enchente para os não afetados leva à "morte", "doença", "desabrigados", "preocupações" e "ocupações indevidas", palavras com menor OME.

Assim, o núcleo central "perda" é determinado pela natureza do objeto representado pelo sistema de valores sociais que o grupo tem em relação a esse objeto, fornecendo o significado à representação e permitindo o estudo comparativo das representações sociais (Abric, 2000) entre os moradores de Governador Valadares afetados e os não afetados pelas enchentes. Sendo então o núcleo central comum entre os dois grupos, coletivamente partilhado, ele define a homogeneidade dos grupos sociais.

Segundo Sá (1998), a TRS estuda as realidades sociais, os fenômenos que envolvem algumas características fundamentais da vida diária daqueles fenômenos que incomodam as rotinas de um grupo de pessoas. Uma representação social emerge onde há perigo para a identidade coletiva, quando a comunicação dos conhecimentos submerge as regras da sociedade. Nessa teoria o sujeito é ativo, faz escolhas, combina e reinventa as imagens carregadas de representações sociais e recorre a essas para compreender as situações que o despertam, para tomar atitudes e emitir opiniões (Moscovici, 2012).

TABELA 5 - Quadro das quatro casas do termo indutor "enchentes" dos moradores de Governador Valadares não afetados pelas enchentes. Governador Valadares/MG, 2014.

\begin{tabular}{|c|c|c|c|c|c|c|}
\hline $\mathrm{OME}^{1}$ & $<2,5$ & & & $\geq 2,5$ & & \\
\hline FME $^{2}$ & Termo evocado & FME & OME & Termo evocado & FME & OME \\
\hline \multirow{7}{*}{$\geq 10$} & Perda & 76 & 2,33 & Poluição & 58 & 2,59 \\
\hline & Preocupação & 74 & 2,10 & Degradação & 37 & 2,60 \\
\hline & Doença & 39 & 2,00 & Tristeza & 27 & 2,89 \\
\hline & Perigo & 37 & 2,30 & Descaso & 18 & 2,50 \\
\hline & Desabrigados & 35 & 2,00 & Água & 18 & 2,72 \\
\hline & Ocupações indevidas & 25 & 2,12 & Inundação & 17 & 2,59 \\
\hline & Morte & 23 & 1,96 & Assoreamento & 12 & 2,92 \\
\hline \multirow{3}{*}{$<10$} & Difícil acesso & 5 & 2 & Animais & 6 & 3,17 \\
\hline & & & & Tranquilidade & 5 & 2,80 \\
\hline & & & & Ausência de governantes & 5 & 3,40 \\
\hline
\end{tabular}

${ }^{1} \mathrm{OME}$ (ordem média de evocações); ${ }^{2} \mathrm{FME}$ (frequência média de evocações); ${ }^{3} \mathrm{FE}$ (frequência de evocação). FONTE: os autores. 
Como complemento indispensável do núcleo central entra em cena o sistema periférico. "Poluição" faz parte da primeira periferia das representações dos moradores de Governador Valadares não afetados, assim como os afetados pelas enchentes, pois foi a palavra evocada com maior FME. As palavras de menor OME foram: "descaso", "poluição", "inundação", “degradação”, “água”, "tristeza”. Nota-se que os atributos "poluição" e "tristeza" são comuns como elementos da primeira periferia dos afetados e dos não afetados pelas enchentes. Os elementos periféricos são mais acessíveis, vivos e concretos e dão representação à realidade (Abric, 2000).

No possível elemento de contraste destaca-se o “difícil acesso". Os moradores não afetados consideram a enchente como perda, que leva ao difícil acesso ao rio. Essa representação difere daqueles que sofreram a enchente e que foram afetados pelo "assoreamento", convivendo com a "ausência" dos governantes e as "ocupações indevidas".

$\mathrm{Na}$ última periferia encontram-se as evocações de menor FME e maior OME. A palavra mais frequente foi "animais" e as de menor OME foram: "tranquilidade", "animais" e "ausência de governantes". A enchente gera perda, prejudica a tranquilidade da vida dos animais, devido à ausência dos governantes.

\section{Considerações finais}

Os resultados deste estudo evidenciam uma problemática preocupante que envolve a relação social e histórica do homem com o meio ambiente. Os moradores de Governador Valadares avaliados representam o Rio Doce como um rio poluído, não havendo diferença para o grupo dos afetados ou não pelas enchentes. Denota-se que essa representação social é cristalizada e permeia o imaginário coletivo desses moradores avaliados, pois, segundo relatos históricos desde a década de 40 , toda a população de Governador Valadares convive com os pântanos, canais e frequentes alagamentos cheios de lixo, não somente às margens do rio, mas em todos os bairros da cidade.

Quando se fala no Rio Doce os moradores estudados logo pensam em poluição, mas há que se considerar também a desordenada ocupação de suas margens, o elevado nível de assoreamento, o aumento dos barramentos que causam estrangulamento da drenagem em alguns pontos, a dramática perda da cobertura florestal na região, a impermeabilização dos terrenos da área da bacia com a intensificação da urbanização. Assim, em se tratando da escolha de um tema a ser abordado nas atividades de educação ambiental com a população, sugere-se começar pela poluição, pois os moradores afetados ou não representam o Rio Doce como um rio poluído.

A primeira periferia diferencia a representação social. Os moradores afetados que sofreram as consequências da enchente falam da "poluição" com mais propriedade: gera mau cheiro, contaminação, doença, prejudica os animais e o lazer devido ao descaso, na maioria das vezes, dos governantes, que não cuidam devidamente do Rio Doce. Para os não afetados, aqueles que não viveram a enchente, a "poluição" causa preocupação, devido ao assoreamento e desmatamento, prejudicando os animais, interferindo no patrimônio e prejudicando a beleza do Rio Doce.

A "perda" é o provável núcleo central da "enchente" evocada pelos moradores de Governador Valadares afetados ou não pelas enchentes, 
mostrando que há homogeneidade de pensamento representacional entre os dois grupos.

A primeira periferia ajuda-nos a diferenciar essa representação. Dessa forma, as enchentes para os moradores afetados levam à perda, geram "preocupação", “doença”, “desabrigados”, devido à "degradação" ocasionada pela "água", ao "descaso" dos governantes, colocando em "perigo" a vida das pessoas. Para os não afetados, a perda sempre é a do outro, levando à "morte", "doença", "desabrigados", "preocupações" e "ocupações indevidas".

Os mecanismos de adaptação a cada nova enchente e a resiliências daqueles que experimentaram as diversas enchentes atuais poderão ser entendidos a partir de experiências daqueles que sofreram o evento.

\section{Agradecimentos}

Os autores agradecem às instituições que apoiaram financeiramente este estudo: Fapemig (Edital 01/2012 - Demanda Universal - Processo número CSA - APQ-00244-12), CNPq (Edital Universal 14/2012 - Processo número 483714/2012-7) e Rede Clima.

\section{Referências}

Abric, J-C. Coopération, Compétition et Représentations Sociales. Fribourg: DelVal. 1987.

Abric, J.-C. Les representations sociales: aspects théoriques. In: Abric, J-C (Org.). Pratiques sociales et représentations. Paris: Presses Universitaires de France, 1994, p. 11-37.

Abric, J.-C. A abordagem estrutural das representações sociais. In: Moreira, A.S.P.; Oliveira, D. C. (Org.). Estudos interdisciplinares de representação social. 2 ed. Goiânia:
AB Editora, 2000, p. 27-38.

Abric, J.-C. Metodología de recolección de las representaciones sociales. In: Abric, J.- C. (Org.). Prácticas sociales y representaciones. México: Ediciones Coyoacán, 2001, p. 53-74.

Abric, J.-C. La recherche du noyau central et de la zone muette des représentations sociales. In: Abric, J.-C. (Org.). Méthodes d'étude des représentations sociale. Ramonville Sant-Agne, France: Érès, 2003, p. 58-80.

Almeida, L. Q.; Carvalho, P. F. A negação dos rios urbanos numa metrópole brasileira. In: XII Encuentro de Geógrafos de América Latina, 2009, Montevidéu. XII Encuentro de Geógrafos de América Latina. Montevidéu: Imprenta Gega, v.1, 2010. Diponível em <http://observatoriogeograficoamericalatina.org.mx/egal12/Geografiasocioeconomica/ Geografiaurbana/281.pdf>. Acesso em: ago. 2014

Abep - Associação Brasileira de Empresas de Pesquisa. Critério de classificação econômica Brasil. Critério Brasil 2014 e a atualização da distribuição de classes para 2014. Disponível em < file://C:/Users/lenovo/Downloads/09_ cceb_2014.pdf> Acesso em: ago. 2014.

Bardin, L. Análise de conteúdo. Lisboa: Edições 70, 2010.

Brasil. Ministério da Saúde. Secretaria de Vigilância em Saúde. Vigilância e Controle da qualidade da água para consumo humano/ Ministério da Saúde, Secretaria de Vigilância em Saúde. Brasília. Ministério da Saúde, 2006. 212 p. (Série B. Textos Básicos de Saúde). Disponível em <http:// bvsms.saude.gov.br/bvs/publicacoes/vigilancia_controle_qualidade_agua.pdf $\#$ page $=18 \& z o o m=$ auto, $-1 \overline{9} 2,742>$. Acesso em: ago. 2014.

Campos, P. H. F. A abordagem estrutural e o estudo das relações entre práticas sociais e representações sociais. In: Campos, P. H. F.; Loureiro, M. C. S. (Org.). Representações sociais e práticas educativas. Goiânia: Ed. da UCG, 2003, p. 21-36.

Carvalho, N. O. Hidrossedimentologia Prática. $2^{\mathrm{a}}$ ed. Editora Interciência: Rio de Janeiro, 2008.

Coelho, A. L. N. Alterações Hidrogeomorfológicas no Médio-Baixo Rio Doce / ES. 2007. 227f. Tese (Doutorado em Geografia) - Instituto de Geociências, Departa- 
mento de Geografia, Universidade Federal Fluminense, Niterói. 2007. Disponível em <http://pct.capes.gov.br/ teses/2007/969121_5.PDF>

Dagnino, R. S. Riscos ambientais na Bacia Hidrográfica do Ribeirão das Pedras, Campinas. Campinas. 2007. 137 f. Dissertação (Mestrado em Geografia) -. Universidade Estadual de Campinas, 2007. Disponível em $<$ http://repositorio.unicamp.br/jspui/bitstream/REPOSIP/287727/1/ Dagnino_RicardodeSampaio_M.pdf>

ESRI - Environmental System Research Institute . World Imagery [basemap]. Scale Not Given. World Imagery Map. February 19, 2012. Disponível em: <http://www.arcgis.com/ home/item.html?id=30e5fe3149c34dflba922e6f5bbf808f $>$. Acesso em: out. 2018.

Espíndola, H. S. A. A história de uma formação socioeconômica urbana: Governador Valadares. Varia História, 9, Belo Horizonte: Depto de História da Fafich, 1998.

Espíndola, H. S. A. Associação Comercial de Governador Valadares: 60 anos de história. Governador Valadares/MG: ACGV, 1999.

Fagundes, B. A problemática da água como representação social. Jundiaí: Paco Editorial, 2015.

Folha Online. 17 de janeiro de 2003. Pior enchente de Minas Gerais foi em 79. Disponível em <http://www1.folha.uol. com.br/folha/cotidiano/ult95u66816.shtml>. Acesso em: abril 2015.

Fraser, M. W.; Galinsky, M. J.; Richman, J. M. Risk, protection, and resilience: Toward a conceptual framework for social work practice. Social Work Research, 23(3), 131-143, 2006. doi: 10.1093/swr/23.3.131.

Genovez, P. F.; Vilarino, M. T. B. Entre práticas sanitárias e saberes tradicionais: a territorialização do saneamento do Médio Rio Doce. In: Espíndola, H. S.; Abreu, J. L. N. (Orgs.). Território, sociedade e modernização: diálogos interdisciplinares. Governador Valadares: Editora Univale, 2010. p. 110-116.

Guedes, R. G.; Genovez, P. F.; Vilarino, M. T. B. Eventos extremos numa perspectiva interdisciplinar, multi-escalar e multi-método: uma abordagem territorial. In: Guedes, R. G.; Ojima, R. (Orgs.). Território Mobilidade Populacional e Ambiente. Governador Valadares: Ed. Univale, 2012. p. 23- 57.

Guedes, R. G.; Simão, A. B.; Dias, C. A.; Braga, E. Uso do Rio e Percepção sobre Risco de Contaminação por Doenças Hídricas no Vale do Rio Doce: evidências estatísticas e narrativas. Cadernos de Saúde Pública, 31(6), 1257-1268, 2015. doi: 10.1590/0102-311X00063514

Hogan, D.; Marandola, Jr., E. Toward and interdisciplinary conceptualization of vulnerability. Population, Space and Place, 11, 455-471, 2005. doi: 10.1002/psp.401

Hora, A. M.; Dias, C. A.; Guedes, G. R.; Costa, A. S. V.; Júnior, M. J. F. Da exploração econômica da bacia hidrográfica do Rio Doce ao atual processo de degradação de seus recursos naturais. In: Guedes, G. R; Ojima, R. (Orgs.). Território Mobilidade Populacional e Ambiente. Governador Valadares: Ed. Univale, 2012. p. 201-234.

Hora, A. M. Representações sociais da comunidade de Tumiritinga sobre o Rio Doce e a Prainha do Jaó. Governador Valadares. 230 f. Dissertação (Mestrado em Gestão Integrada do Território) - . Universidade Vale do Rio Doce. Governador Valadares, 2013.

IBGE - Instituto Brasileiro de Geografia e Estatística. Sinopse do Censo Demográfico 2010a. Distribuição da população por sexo segundo os grupos de idade. Disponível em: < https://censo2010.ibge.gov.br/sinopse/index.php?dados=26\&uf=31\#topo_piramide $>$. Acesso em: dez 2015.

IBGE - Instituto Brasileiro de Geografia e Estatística. Banco de Dados Agregado. Censo Demográfico 2010b. Disponível em: <https://biblioteca.ibge.gov.br/visualizacao/periodi$\cos / 552 /$ cd_2010_agsn_if.pdf $>$. Acesso em: dez 2015.

IBGE - Instituto Brasileiro de Geografia e Estatística. Governador Valadares. 2013. Disponível em: < https:// ww2.ibge.gov.br/cidadesat/xtras/perfil.php?lang=\&codmun $=312770 \&$ search $=$ minas-gerais $\mid$ governador-valadares>. Acesso em: dez 2015.

IBGE - Instituto Brasileiro de Geografia e Estatística. IBGE. Malha Digital dos Municípios Brasileiros 2015. IBGE, Rio de Janeiro, 2018. Disponível em: <https://mapas.ibge.gov. $\mathrm{br} /$ bases-e-referenciais/bases-cartograficas/malhas-digitais>. Acesso em: out. 2018. 
IGAM - Instituto Mineiro de Gestão das Águas. Plano Integrado de Recursos Hídricos da Bacia do Rio Doce e dos Planos de Ações de Recursos Hídricos para as Unidades de Planejamento e Gestão de Recursos Hídricos no Ámbito da Bacia do Rio Doce. Consórcio Ecoplan Lume, Belo Horizonte, 2010.

Jansen, M. A.; Ostrom, E. (Eds.). Resilience, vulenarabilty and adaptation: a cross-cutting theme of International Human Dimensions Programme on Global Environmental Change. Special issue of Global Environmental Change, 16(3), 240-252, 2006. doi: 10.1016/j.gloenvcha.2006.04.003

Moscovici, S. Representações sociais - investigações em psicologia social. 2. ed. Petrópolis: Vozes, 2004.

Moscovici, S. A psicanálise, sua imagem e seu público. Petrópolis: Ed. Vozes, 2012.

Oliveira, D. C. Análise das Evocações Livres: uma técnica de análise estrutural das representações sociais. In: Moreira, A. S. P.; Camargo, B. V.; Jesuíno, J. C.; Nóbrega, S. M. (Org.). Perspectivas Teórico-Metodológicas em Representações Sociais. João Pessoa: Editora Universitária UFPB, 2005, p. 573-603.

Oliveira, D. B. de. et al. A representação social do meio ambiente na leitura comunitária do Plano Diretor de Palmas (TO). Desenvolvimento Meio Ambiente, 35, 429-445, 2015. doi: 10.5380/dma.v35i0.41662
Porath, S. L. A Paisagem de Rios Urbanos. A Presença do Rio Itajaí-Açu na Cidade de Blumenau. 2004. 150f. Florianópolis. Dissertação (Mestrado em Arquitetura e Urbanismo) -Universidade Federal de Santa Catarina.

Phir Doce - Plano integrado de recursos hídricos da bacia hidrográfica do Rio Doce e planos de ações para as unidades de planejamento e gestão de recursos hídricos no âmbito da bacia do Rio Doce. v. I; 2010. Disponível em: http://www.cbhdoce.org.br//wp-content/uploads/2016/12/ PIRH_Doce_Volume_I.pdf $>$ Acesso em: fev. 2014.

Sá, C. P. A construção do objeto de pesquisa em representações sociais. Rio de Janeiro: Ed. UERJ, 1998.

Sá, C. P. Núcleo central das representações sociais. 2 ed. Petrópolis: Vozes, 2002.

Sampaio, N.; Vargas, M. A. M. A paisagem simbólica do Rio Pardo: As práticas culturais da comunidade ribeirinha e das lavadeiras de roupa do Rio em Itambé no Sudoeste da Bahia. In: ENDITRANS - Tecendo conhecimentos em complexidade: Desafios e estratégias, Vitória da Conquista: 2010. Disponível em: <http://www.uesb.br/recom/anais/ artigos/03/A paisagem simbólica do Rio Pardo-As práticas culturais da comunidade ribeirinha e das lavadeiras de roupa do Rio em Itambé no Sudoeste-BA.pdf $>$. Acesso em: dez 2015.

Vergès, P. Ensemble de programmes permettant version 2. Aix-en-Provence: LAMES, 2000. 